doi:10.32620/oikit.2018.81.05

УДК 621.7.044

Е.А. Фролов, С.Г. Ясько, С.И. Кравченко

\title{
Технологические возможности пневмоударной штамповки вытяжкой тонколистовых деталей
}

\section{Полтавский национальный технический университет имени Юрия Кондратюка}

\begin{abstract}
Определены параметры десормирования при высокоскоростной вытяжке осесимметричных тонколистовых заготовок, обеспечивающих фоормообразование деталей без искажения фрормы рельефа и разрушения металла методом пневмоударной штамповки. На основании проведенных исследований установлены технологические возможности изготовления качественных осесимметричных тонкостенных деталей методом пневмоударной штамповки вытяжкой. Условия устойчивости заготовки при формовке осесимметричных элементов несферической фрормы подобны условиям устойчивости заготовки при фрормовке сферических элементов. Полученные результаты можно распространить и на вытяжку эллиптических, неглубоких конических и других близких к ним по форме деталей. Пневмоударная штамповка позволяет вытягивать куполообразные детали без применения перетяжных порогов, двухпереходной штамповки и других специальных приемов с относительной толщиной заготовки в два - четыре раза меньше, чем допускается при вытяжке пуансоном.
\end{abstract}

Ключевые слова: пневмоударная штамповка, вытяжка, формовка, дефекты, устойчивость, купол, рельеф, деталь, заготовка.

Важной проблемой пластического фрормообразования листового металла является устойчивость процесса деформирования, являющаяся одним из основных условий получения штампованных деталей высокого качества. Потеря устойчивости формообразования приводит к возникновению значительных местных деформаций, разрушению металла или искажению фрормы детали [1-3]. Особенно это проявляется при высокоскоростном деформировании тонколистовых заготовок $[4,5]$.

Целью работы является определение параметров деформирования при высокоскоростной вытяжке осесимметричных тонколистовых заготовок, обеспечивающих фоормообразование деталей без искажения фрормы рельефа и разрушения металла методом пневмоударной штамповки (ПУШ).

Листовая заготовка малой толщины при вытяжке может получить следующие типы потери устойчивости: волнистость (образование складок), неравномерность вытяжки фланца, наличие вмятин на купольной части и сосредоточенное утонение (рис. 1.)
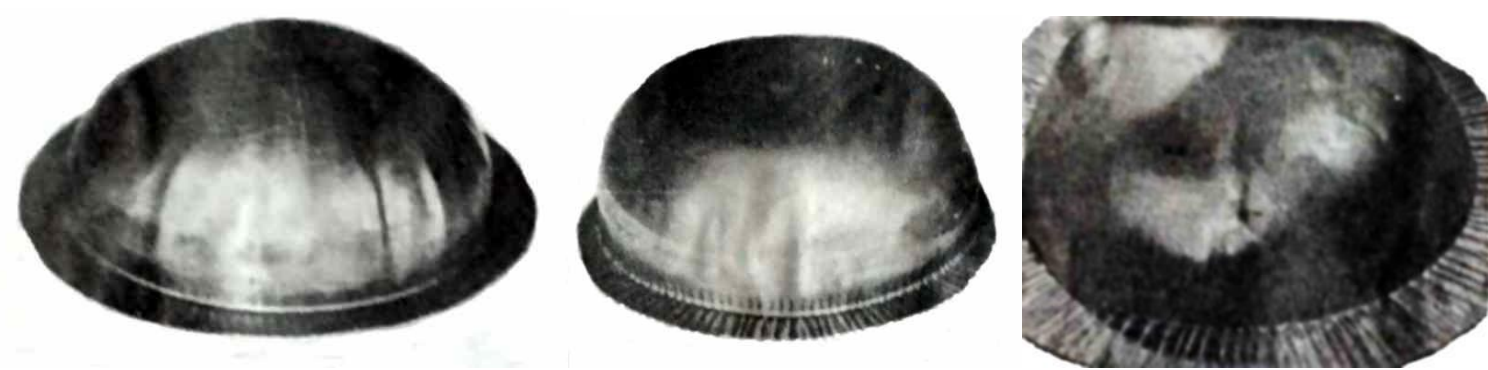

Рис. 1. Отштампованные тонколистовые детали с различными типами потери устойчивости при пневмоударной штамповке жидкостью 
Проявление того или иного типа потери устойчивости зависит от напряженного состояния, скорости деформирования, анизотропии, механических свойств материала и других факторов.

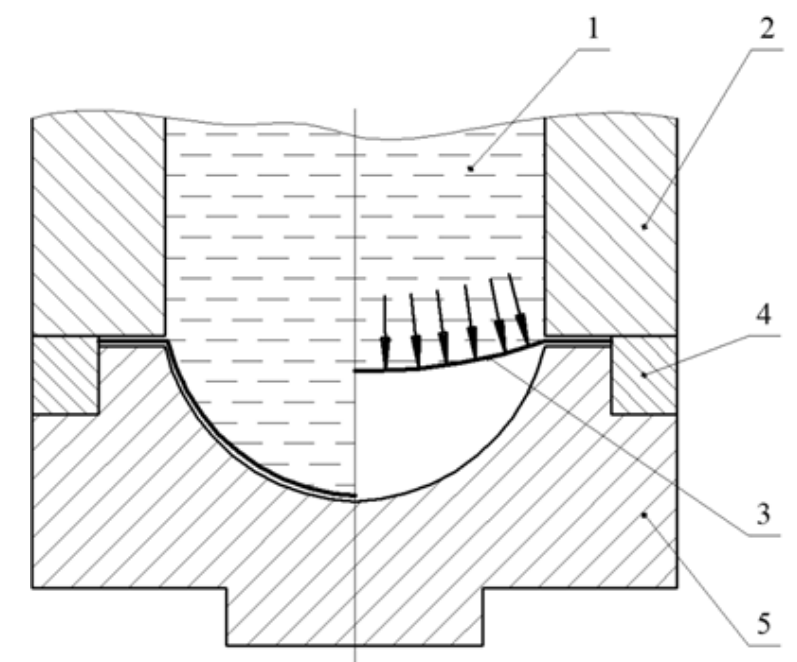

Рис. 2. Типовая схема вытяжки деталей жидкостью со сорерическим дном

Потеря устойчивости наиболее вероятна при получении деталей из тонких заготовок с использованием высокоскоростного локального нагружения. В этом отношении наиболее характерен процесс вытяжки часто встречающихся куполообразных деталей со сорерическим и эллиптическим дном.

В процессе вытяжки (рис. 2) тонколистовая заготовка 3, уложенная в трафраретное кольцо 4, зажимается между прижимным кольцом 2 и матрицей 5 и вытягивается жидкостью 1 в матрицу. При вытяжке зажатой оказывается только часть заготовки в виде кольца, остальная часть остается свободной. Чем больше свободная поверхность заготовки (между пуансоном и матрицей), тем больше вероятность потери устойчивости за счет сжимающих напряжений на данном участке с образованием складок. Для предотвращения образования складок прибегают к увеличению радиальных растягивающих напряжений, что достигается увеличением трения между прижимом и фрланцем заготовки путем урегулирования усилия прижима, использованием тормозных ребер или изменением обратного (реверсивного) способа вытяжки. Увеличение трения между прижимом и фрланцем сопровождается увеличением деформирующего усилия и соответственно растягивающих напряжений в опасном сечении заготовки, что может привести к появлению сосредоточенного утонения, разрывов и другим видам потери устойчивости.

Теоретически устойчивость заготовки может быть рассмотрена с использованием энергетического метода [6], согласно которому устойчивое состояние заготовки характеризуется условием $U \geq A$, где $U$-работа внутренних сил, препятствующая потере устойчивости; $A$ - работа внешних сил на контуре элемента.

C помощью совместного решения уравнений для работы внешних и внутренних сил установлено [6], что исходя из значения критического напряжения устойчивости можно найти предельное значение относительной толщины заготовки при вытяжке деталей со сферическим дном

$$
\left(\frac{S}{D_{3}}\right)_{n p}=0,11 \sqrt{\frac{S}{R_{c \phi}}},
$$

где $\mathrm{R}_{\text {сф }}$ - радиус сфреры дна; $\mathrm{S}$ - толщина заготовки. 


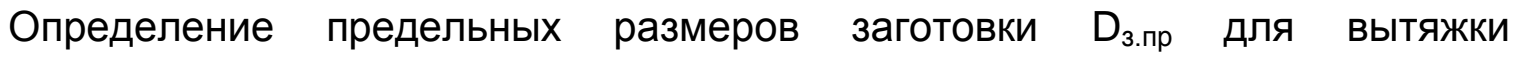
сорерических днищ при минимальном усилии прижима, достаточном для удержания складкообразования фрланца, $q_{0}=0,01 \cdot \sigma_{T}$ можно выполнять по более простой зависимости

$$
\frac{S}{D_{3 . n p}} \cdot 100 \% \geq 0,57
$$

Если увеличить усилие прижима до 0,02 $\sigma_{T}$, то относительную толщину заготовки можно уменьшать, при этом утонение, хотя оно и увеличивается, не будет превышать допустимую величину 15 \%. В этом случае для сорерических днищ

$$
\frac{S}{D_{\text {з.np }}} \cdot 100 \% \geq 0,485 .
$$

Таким образом, можно считать, что предельно допустимая относительная толщина заготовки при вытяжке полусферических днищ с плоским прижимом равна $0,45 \ldots 0,50 \%$.

Вытяжка с плоским прижимом на пневмоударной установке Т-1324 позволяет использовать заготовки без потери устойчивости с меньшей относительной толщиной, чем в штампе. Так, за одну операцию без специальных конструктивных мероприятий и промежуточных отжигов вытягивалась деталь «полусфрера» (рис. 3) при коэфффициенте вытяжки $\mathrm{k}=1,69$ и относительной толщине заготовки 0,42 \%, что в 3 раза меньше расчетной - при вытяжке пуансоном по зависимости (1) и в 1,1-1,2 раза меньше предельной - при вытяжке с большим усилием прижима.
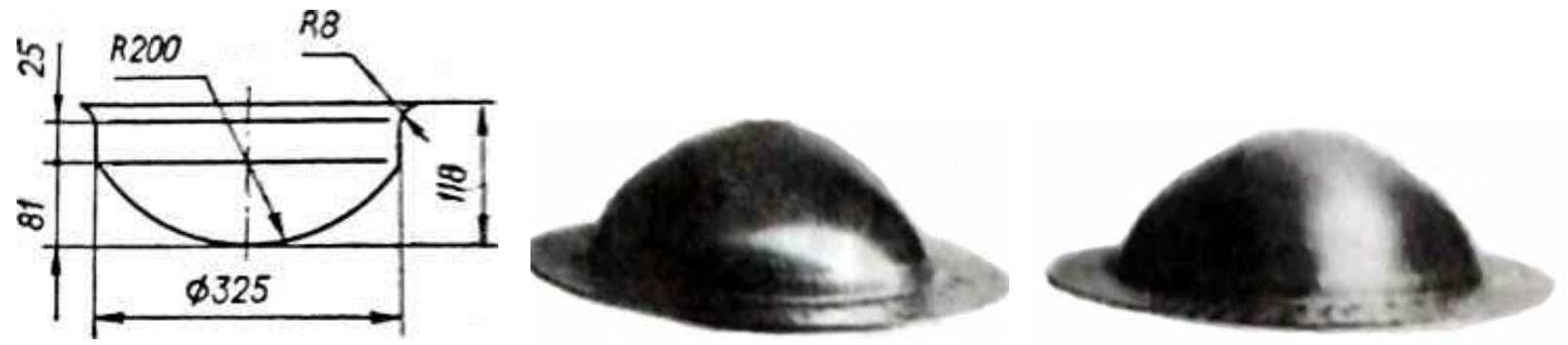

Рис. 3. Цилиндрическая деталь со сферическим днищем

Кроме того, на установке Т-1324 пневмоударной вытяжкой получены сферические днища диаметром до 440 мм при относительной толщине 0,23 \%, что в 4,15 раза меньше расчетной при коэффрициенте вытяжки $\mathrm{k}=1,55$ за одну операцию и в 1,9 - 2,2 раза меньше предельной.

Таблица 1

\begin{tabular}{|c|c|c|c|c|c|}
\hline $\begin{array}{c}\text { Толщина } \\
\text { S, мм }\end{array}$ & $\begin{array}{c}\text { Диаметр } \\
D_{3}, \text { мм }\end{array}$ & Материал & $\begin{array}{c}\text { Относитель- } \\
\text { ная } \\
\text { толщина } \\
\mathrm{S} / \mathrm{D}_{3} \cdot 100 \%\end{array}$ & $\begin{array}{l}\text { Допустимая } \\
\text { расчетная } \\
\text { толщина } \\
\mathrm{S} / \mathrm{D}_{3} \cdot 100 \% \text { расч }\end{array}$ & $\begin{array}{l}\text { Предельная } \\
\text { относитель- } \\
\text { ная толщина } \\
\mathrm{S} / \mathrm{D}_{3} \cdot 100 \% \text { рас4 }\end{array}$ \\
\hline 1,5 & 650 & Х18Н9T & 0,23 & 0,91 & $0,455-0,5$ \\
\hline 0,8 & 189 & $\begin{array}{c}\text { Сталь } \\
\text { 10кп }\end{array}$ & 0,42 & 1,29 & $0,455-0,5$ \\
\hline
\end{tabular}

Характеристики полученных ПУШ деталей со сферическим дном 
Продолжение таблицы 1

\begin{tabular}{|c|c|c|c|c|c|}
\hline 0,8 & 380 & Х18Н10Т & 0,31 & 0,89 & $0,455-0,5$ \\
\hline 1,5 & 450 & Сталь 3 & 0,33 & 0,82 & $0,44-0,5$ \\
\hline
\end{tabular}

Коэффрициенты вытяжки соответственно равны 1,78 и 1,38, а относительные толщины - 0,31 и 0,33\%, что в 4,2 и 2,5 раза меньше расчетной для вытяжки пуансоном и в 2,06-2,38 и 1,38-1,51 раза меньше предельно допустимой.

При ПУШ штамповке прижим может осуществляться путем применения неподвижной прижимной плиты, зафиксированной в период деформирования на постоянном расстоянии, несколько большем толщины исходной заготовки, обычно в 1,1-1,2 раза. Величина гарантированного зазора принимается минимальной при конструктивном фрланце и приближается к максимальному значению при удаляемом технологическом фланце. При необходимости в каждом конкретном случае значение зазора уточняется экспериментально в целях обеспечения требуемого качества штампуемых деталей.

Величина давления прижима может быть рассчитана исходя из удельного давления прижима. Если приведенную в работе [7] фрормулу преобразовать так, чтобы удельное давление прижима зависело от относительной толщины заготовки и коэффрициента вытяжки, то она примет вид

$$
q=0,0025\left[(k-1)^{2}+\frac{1}{2 k \frac{S}{D_{3}} \cdot 100}\right] \cdot \sigma_{b} .
$$

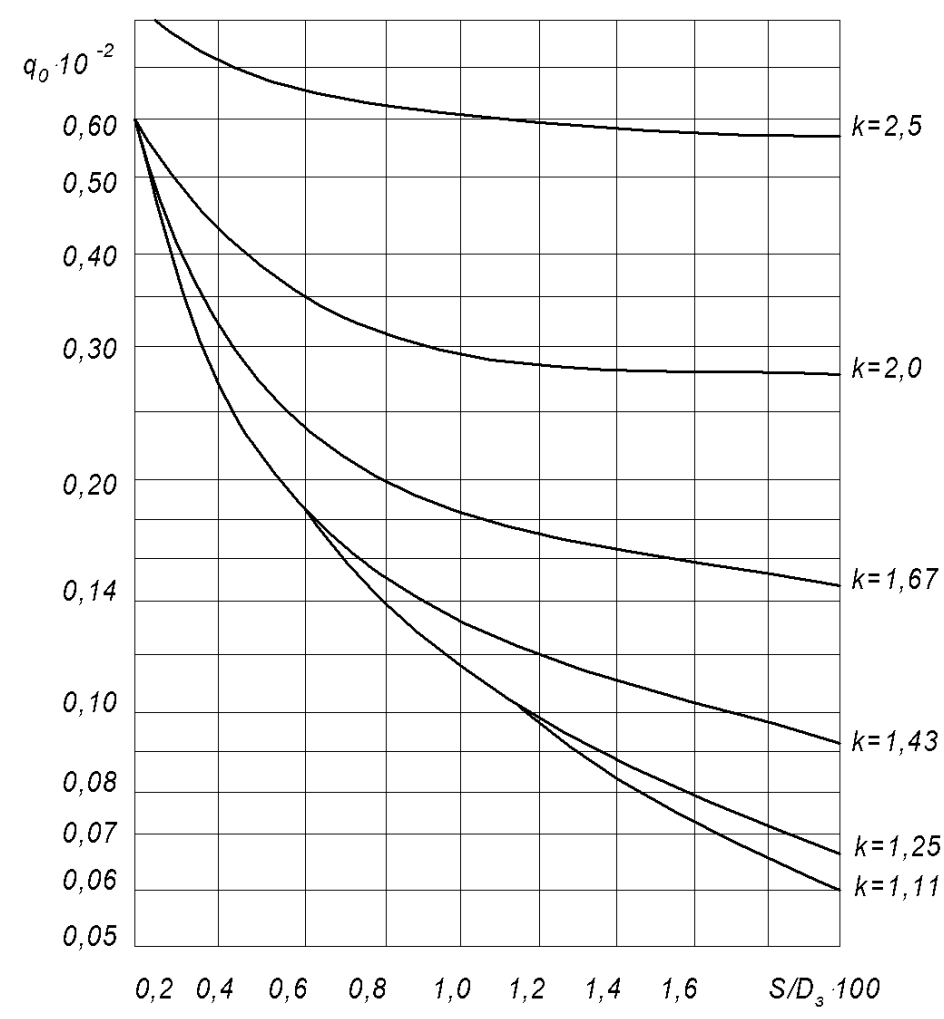

Рис. 4. Зависимость удельного давления прижима от относительной толщины заготовки для материала с единичным пределом прочности 
Значения удельных давлений для каждого конкретного случая могут быть рассчитаны по выражению $q=q_{0} \cdot \sigma_{6}$, где $q_{0}$ - удельное давление прижима для виртуального материала с пределом прочности равным единице, а также может быть определено из графика, показанного на рис. 4.

Таблица 2

Технологические возможности ПУШ вытяжкой на установке Т-1324

\begin{tabular}{|c|c|c|c|}
\hline $\begin{array}{c}\text { Отношение } \\
\frac{S / D_{3} \cdot 100 \%_{\text {pacu }}}{S / D_{3} \cdot 100 \%}\end{array}$ & $\begin{array}{c}\text { Отношение } \\
\frac{S / D_{3} \cdot 100 \%_{n p}}{S / D_{3} \cdot 100 \%}\end{array}$ & $\begin{array}{c}\text { Коэфрфициент } \\
\text { вытяжки } \\
\mathrm{D}_{3} / \mathrm{d}\end{array}$ & Вид прижима \\
\hline 3,95 & $1,98-2,17$ & 1,69 & $\begin{array}{c}\text { Прижим на } \\
\text { заготовку }\end{array}$ \\
\hline 3,08 & $1,08-1,18$ & 1,69 & То же \\
\hline 4,23 & $2,06-2,38$ & 1,78 & $\begin{array}{c}\text { Фиксированный } \\
\text { зазор 0,95 мм }\end{array}$ \\
\hline 2,50 & $1,38-1,51$ & 1,38 & $\begin{array}{c}\text { Прижим на } \\
\text { заготовку }\end{array}$ \\
\hline
\end{tabular}

Основываясь на результатах вытяжки на установке Т-1324 полусферических и близких к ним по форме днищ, можно сделать вывод, что ПУШ позволяет вытягивать куполообразные детали без применения перетяжных порогов, двухпереходной штамповки и других специальных приемов с относительной толщиной заготовки в два - четыре раза меньше (табл. 2), чем допускается при вытяжке пуансоном.

Если предельную относительную толщину заготовки рассчитывают с использованием зависимости, выведенной в работе [6] для вытяжки пуансоном, то применительно к ПУШ вытяжкой, как показали эксперименты, коэфффициент в зависимости (1) может быть уменьшен в четыре раза:

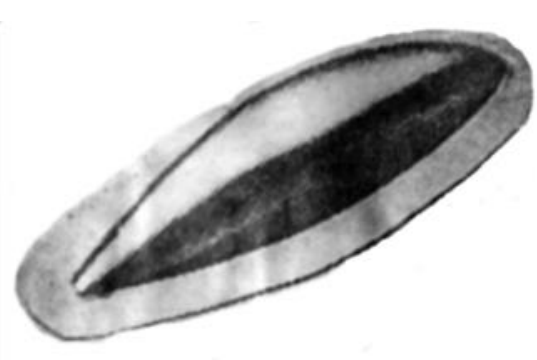

Рис. 5. Внешний вид детали типа «обтекатель»

$$
\left(\frac{S}{D_{3}}\right)_{n p}=0,027 \sqrt{\frac{S}{R_{c \phi}}}
$$

Учитывая, что условия устойчивости заготовки при формовке осесимметричных элементов несферической фрормы примерно подобны условиям устойчивости заготовки при формовке сфрерических элементов, полученные результаты можно распространить и на вытяжку эллиптических, неглубоких конических и других близких к ним по фрорме деталей (рис. 5).

Исследования показали, что при ПУШ вытяжкой увеличение радиуса перетяжного ребра матрицы положительно сказывается до величины $R_{M}=10 \mathrm{~S}$.

\section{Выводы}

На основании проведенных исследований установлены технологические возможности изготовления качественных осесимметричных тонкостенных деталей методом ПУШ вытяжкой. 


\section{Список литературы}

1. Головлев, В. Д. Расчеты процессов листовой штамповки (Устойчивость формообразования тонколистового металла) / В. Д. Головлев. - М. : Машиностроение, 1974. - 136 с.

2. Пановко, Я. Г. Устойчивость и колебание упругих систем / Я. Г Пановко, И. И. Губанова. - М. : Наука, 1967. - 280 с.

3. Матвеев А.Д. Испытание листового материала на осесимметричное растяжение. //«Кузнечно-штамповочное производство» 1971. - № 10 -С. 14-17.

4. Орленко, Л. П. Поведение материалов при интенсивных динамических нагрузках /Л. П. Орленко. - М. : Машиностроение, 1964. - 167 с.

5. Фролов, Е.А. Аналитическое исследование параметров точности вытяжных операций пневмоударной штамповки / Е. А. Фролов, И. В. Манаенков, О. Г. Носенко // Открытые информационные и компьютерные интегрированные технологии. - 2013. - Вып. 62. - С. 62-70.

6. Мошнин, Е. Н. Технология штамповки крупногабаритных деталей /

Е.Н. Мошнин. - М.: Машиностроение, 1973. - 240 с.

7. Скворцов, Г.Д. Основы конструирования штампов для холодной листовой штамповки : конструкции и расчеты / Г.Д. Скворцов. - М. : Машиностроение, 1972. $-360 \mathrm{c}$.

Поступила в редакцию 31.08.2018

\section{Технологічні можливості пневмоударного штампування витяжкою тонколистових деталей}

Визначено параметри деформування при високошвидкісний витяжці вісесиметричних тонколистових заготовок, що забезпечують формоутворення деталей без спотворення форми рельєфу і руйнування металу методом пневмоударного штампування. На підставі проведених досліджень встановлено технологічні можливості виготовлення якісних вісесиметричних тонкостінних деталей методом пневмоударного штампування витяжкою. Умови стійкості заготовки при формуванні вісесиметричних елементів несферичної форми подібні до умов стійкості заготовки при фрормуванні сферичних елементів. Отримані результати можна поширити і на витяжку еліптичних, неглибоких конічних та інших близьких до них за формою деталей. Пневмоударне штампування дозволяє витягувати куполоподібні деталі без застосування перетяжних порогів, двохперехідного штампування та інших спеціальних прийомів 3 відносною товщиною заготовки в два - чотири рази менше, ніж допускається при витяжці пуансоном.

Ключові слова: пневмоударне штампування, витягування, формування, дефекти, стійкість, купол, рельєф, деталь, заготовка. 


\section{Technological Possibilities of Pneumatic Impact Punching by Stretching Thin Sheeted Parts}

The determination of the deformation parameters for high-speed extraction of axisymmetric thin-film blanks that ensure the shaping of parts without distortion of the shape of the relief and destruction of metal by the method of pneumatic impact punching is performed. On the basis of the conducted researches the technological possibilities of manufacturing of quality axisymmetric thin-walled details by the method of pneumatic impact punching are established. The conditions for the stability of the workpiece when forming the axisymmetric elements of a non-spherical shape are similar to the conditions for the stability of the workpiece during the shaping of spherical elements, and the results can be extended to the drawing of elliptical, shallow conical and other similar parts. Pneumatic impact punching allows you to pull dome-shaped parts without the use of hanging thresholds, two-transversal stamping and other special techniques with a relative billet thickness of two to four times less than allowed when drawing a punch.

Keywords: pneumatic impact stamping, drawing, forming, defects, stability, domed, relief, detail, workpiece.

Сведения об авторах:

Фролов Евнений Андреевич, д-р техн. наук, проф., Полтавский национальный технический университет имени Юрия Кондратюка, г. Полтава, Украина. e-mail: frolov.poltntu@gmail.com.

Ясько Станислав Георгиевич, ст. преподаватель, Полтавский национальный технический университет имени Юрия Кондратюка, г. Полтава, Украина, e-mail: s.g.yasko@gmail.com; ORCID:0000-0001-6228-705X.

Кравченко Сергей Иванович, кандидат техн. наук, доцент, зав. каф. технології машинобудування, Полтавский национальный технический университет имени Юрия Кондратюка, г. Полтава, Украина, e-mail: 050Ser09@i.ua 